\title{
MINIMALLY INVASIVE UROLOGICAL INTERVENTIONS IN OUTPATIENT CLINIC ON THE EXAMPLE OF PROSTATE BIOPSY
}

\author{
Ashot Gevorkyan \\ Department of Urology \\ branch No. 2 - Polyclinic No. 195 \\ Western Administrative District of Moscow \\ 31/1 Molodogvardeyskaya str., Moscow, Russian Federation, 123467 \\ ashot_gevorkyan@mail.ru \\ Maxim Ishmuratov \\ Department of Urology \\ branch No. 2 - Polyclinic No. 195 \\ Western Administrative District of Moscow \\ 31/1 Molodogvardeyskaya str., Moscow, Russian Federation, 123467 \\ Ilya Lumpov \\ Clinic of Urology of I. M. Sechenov First MSMU Russia (Sechenov University) \\ 2 Bolshaya Pirogovskaya str., Moscow, Russian Federation, 119435 \\ Urology27@mail.ru \\ Samvel Petrosyan \\ Department of Urology \\ branch No. 2 - Polyclinic No. 195 \\ Western Administrative District of Moscow \\ 31/1 Molodogvardeyskaya str., Moscow, Russian Federation, 123467 \\ Petrosyan_sg@mail.ru \\ Daniel Sharshunov \\ Department of Urology \\ branch No. 2 - Polyclinic No. 195 \\ Western Administrative District of Moscow \\ 31/1 Molodogvardeyskaya str., Moscow, Russian Federation, 123467 \\ Dr.sharshunov@gmail.com
}

\begin{abstract}
One of the main directions of improving medical care was the introduction of inpatient forms of medical care for patients who do not require round-the-clock supervision.

Aim of the research: to prove the effectiveness and economic feasibility of minimally invasive procedures in outpatient conditions.

Materials and methods. The study included 3524 patients in the period from 2010 to 2017, who underwent transrectal prostate biopsy on the basis of the Department of urology of polyclinic No. 195 of the Western district of Moscow. For comparison, the patients were taken, who underwent a biopsy of the prostate gland at the base hospital No. 31, No. 51, No. 17.

Results. The average number of biopsies performed in hospital No. 31, No. 51 and No. 17 for the year amounted to 344 biopsies, and the average detectability of prostate cancer was $142(41.3 \%)$. The average number of biopsies per year in the urology department of the branch number 2 GP No. 195 amounted to 440.5, and the average detectability of prostate cancer 152.8 (34.7\%). Thus, with comparable inpatient detection of prostate cancer in one large outpatient urology center, an average of $28 \%$ more biopsies are performed (440.5 versus 344 ) than in 3 hospitals over a comparable period of time.

Conclusions. Inpatient technologies can reduce the burden on hospitals. The development of hospital-replacing forms is determined by the need of the population and for efficient use of financial and technical resources of health care.
\end{abstract}

Keywords: inpatient technologies, prostate biopsy, day hospital, prostate cancer. 


\section{Introduction}

Order of the Government of the Russian Federation No. 2511-p dated December 24, 2012 approved the "Concept of Healthcare Development of the Russian Federation" suggesting the introduction of new and development of existing technologies used outside the hospital, which will allow not only to carry out highly effective diagnostics and treatment, but also to effectively spend financial resources. Today, much of the traditional inpatient surgical care and invasive manipulations are moved to the outpatient unit. The most effective, proven and internationally recognized, in accordance with the federal law "On Strategic Planning in the Russian Federation", are health-saving technologies based on conducting mass-directed health screenings as part of clinical examinations and preventive examinations on an outpatient basis $[1,2]$. These include one of the most important oncological tasks - early diagnosis of prostate cancer.

Prostate gland is the male sexual gland which is present in front of the rectum and between the bladder and penis [3]. Prostate cancer (prostate cancer) is one of the most important medical problems concerning the male population. Age is the major risk factor but there is also an increased risk in those with a family history of either prostatic or breast cancer [4]. Incidence and mortality rates for prostate cancer are highly variable worldwide $[5,6]$.

In terms of prevalence in Europe ( $>200$ cases of morbidity per 100,000 population), this malignancy exceeds the incidence of lung cancer and colorectal cancer [7, 8]. In addition, currently in the structure of cancer incidence of prostate cancer is in second place after lung cancer and in third place in the structure of mortality [7, 9]. In Russia, the incidence of prostate cancer is steadily increasing: over the past 1.5 decades, it has increased almost 2 times; only 2010 registered 107942 patients [10]. In 2012, 28,560 new cases of prostate cancer were reported in Russia, with a morbidity rate of 40.1 per 100,000 males [11].

It is 2 to 3 times more in person whose brother or father has prostate cancer as compared to those who have no family history of prostate cancer. If a person has three immediate family members suffering from prostate cancer then there is 10 times more chance of prostate cancer as compared to person that has no family history of prostate cancer. High fat diet also increases the chance of prostate cancer $[12,13]$.

Patients may be asymptomatic but the commonest complaint is difficulty with micturition, straining to start, frequency, and nocturia. All these can arise from benign prostatic hypertrophy as well as malignancy. Obstructive voiding symptoms are most often due to benign prostatic hyperplasia which occurs in the same age group. Malignant changes occur in prostate cells that further proceed toward carcinoma. Environmental and genetic influences cause promotional proceedings and sequence of commencement.

Prostate specific antigen increases in enlarged prostate gland, older age, prostatitis, ejaculation, riding a bicycle, certain urologic conditions and certain medications [14]. Prostate specific antigen decreases in 5-alpha reductase inhibitors, herbal mixtures, obesity, aspirin use, thiazide diuretic, statin. Patients with intermediate levels of PSA usually have localized and therefore potentially curable cancers.

The widespread use of prophylactic studies of men to identify prostate cancer by determining the level of prostate-specific antigen (PSA) led to a significant increase in the number of prostate gland biopsies (PG), a method currently recognized as the "gold standard" for diagnosing prostate cancer.

PG biopsy provides the physician with the necessary information on the presence of altered prostate tissue, namely: high and low prostate intraepithelial neoplasia (PIN), atypical small acinar hyperplasia or prostate cancer, tumor localization, its length in the biopsy, the presence of perineural, perivasal invasion, the stage of differentiation of tumor cells (gradation on the Gleason scale) $[15,16]$. Biopsy is the final stage of primary diagnosis of prostate cancer and the basis for starting timely adequate treatment, which is especially important in the conditions of increasing the prevalence of this disease [17].

Thus, given the steady increase in the incidence of prostate cancer, it is not surprising that a prostate biopsy, an invasive diagnostic procedure, was one of the first to appear in the outpatient urology. 


\section{Aim of research}

To prove the effectiveness and economic feasibility of minimally invasive procedures in outpatient conditions.

\section{Materials and methods}

On the basis of the urology department of branch No. 2 of the state budgetary institution of health care GP No. 195 of the Western Administrative District of Moscow, a service for conducting a number of minimally invasive diagnostic and surgical interventions has been successfully operating for more than 7 years. The centralized coordination of the work of doctors of different levels within the administrative district allows not deviating from the implemented standard methods of invasive manipulations and patient management algorithms.

In the period from 2010 to 2017, the urology department on the basis of the branch No. 2 of the city polyclinic No. 195 of the Western District of Moscow was sent for further examination in connection with suspected PCa 3524 patients, aged 50 to 78 years (mean age 62 years). A standard examination of patients before a biopsy was to conduct a physical examination, including a digital rectal examination, measurement of PSA, transrectal ultrasound of the RV. Patients with PSA values greater than $4 \mathrm{ng} / \mathrm{ml}$ were given a transrectal multifocal biopsy of the prostate according to the standard procedure of 12 points. Given the outpatient nature of the manipulation, all patients received appropriate training. Preoperative standard examination included clinical, biochemical blood and urine tests, examination of the coagulation system, blood group and Rh factor, necessary tests for the detection of infectious diseases, an electrocardiogram. The patient underwent a mandatory examination by a therapist, and when clinically significant pathologies were identified, they were treated before a prostate biopsy.

A cleansing enema was performed on the night before and on the morning of the manipulation. Antibacterial prophylaxis was usually performed with fluoroquinolone preparations (ciprofloxacin and levofloxacin) a day before the manipulation and continued for 3 days after a prostate biopsy.

\section{Results}

According to the results of histological studies of biopsy material, 3524 patients of the urology department of branch No. 2 of the GP No. 195, prostate cancer were detected in 1224 patients, thus the detectability of prostate cancer was $34.7 \%$.

When discussing the feasibility and effectiveness of inpatient technologies, it is first of all necessary to compare statistical data obtained in outpatient settings with the inpatient hospital indicators of the respective urban district. In the city hospitals of the Western Administrative District, namely, in the urology departments of GKB No. 31, GKB No. 51 and GKB No. 17 in 2010, a total of 313 prostate biopsies were performed, in 2011 - 230 biopsies, for 2012 - 239 biopsies, for 2013 - 295 biopsies, for 2014 - 324 biopsies, for 2015 - 342 biopsies, in 2016 - 292 biopsies, in 2017 - 716 biopsies.

The detectability of prostate cancer for the given years according to the hospitals was 128 (41\%), 129 (56 \%), 96 (40\%), 105 (35.6\%), 180 (55\%), 138 (40.3\%), 142 (48.6\%), 218 (30.5\%) cases of newly diagnosed PCa, respectively. Thus, from 2010 to 2017, 2751 prostate biopsies were performed in city hospitals, and in 1136 men, prostate cancer was verified.

The average number of biopsies performed in all hospitals of the Western Administrative District of Moscow for the year amounted to 344 biopsies, and the average detectability of prostate cancer was $142(41.3 \%)$.

In the urology department of the branch number 2 of the city polyclinic No. 195 in 2010, 236 prostate biopsies were performed, in 2011 - 319 biopsies, for 2012 - 566 biopsies, for 2013 448 biopsies, for 2014 - 554 biopsies, for 2015 - 663 biopsies, in 2016 - 366 biopsies, in 2017 372 biopsies. The detectability of prostate cancer for the given years in this department was 99 (41.9\%), 107 (33.5\%), 197 (34.8\%), 161 (36\%), 204 (36.6\%), 208 (31.3\%), 122 (33\%), 125 (33.6\%) cases, respectively. Thus, for the period from 2010 to 2017 inclusive, the average number of completed biopsies per year in the urology department of the branch number 2 GP number 195 amounted to 440.5, and the average detectability of prostate cancer - 152.8 (34.7\%) (Table 1). 
Table 1

The number of prostate biopsies and frequency of prostate cancer detection for the period 2010-2017

\begin{tabular}{ccccc}
\hline \multirow{2}{*}{ Year } & \multicolumn{2}{c}{ GKB No. 31, 51, 17 } & \multicolumn{2}{c}{ Polyclinic No. 195, branch No. 2 } \\
\cline { 2 - 5 } & Prostate biopsies & Prostate cancer & Prostate biopsies & Prostate cancer \\
\hline 2010 & 313 & $128(41 \%)$ & 236 & $99(41.9 \%)$ \\
2011 & 230 & $129(56 \%)$ & 319 & $107(33.5 \%)$ \\
2012 & 239 & $96(40 \%)$ & 566 & $197(34.8 \%)$ \\
2013 & 295 & $105(35.6 \%)$ & 448 & $161(36 \%)$ \\
2014 & 324 & $180(55 \%)$ & 554 & $204(36.6 \%)$ \\
2015 & 342 & $138(40.3 \%)$ & 663 & $208(31.3 \%)$ \\
2016 & 292 & $142(48.6 \%)$ & 366 & $122(33 \%)$ \\
2017 & 716 & $218(30.5 \%)$ & 372 & $125(33.6 \%)$ \\
Total & 2751 & $1136(41.3 \%)$ & 3524 & $1224(34.7 \%)$
\end{tabular}

From the above data, it follows that with comparable inpatient detection of prostate cancer in one large outpatient urology center, an average of $28 \%$ more biopsies are performed (440.5 versus 344 ) than in three hospitals over a comparable period of time.

With a similar ratio of indicators, inpatient technologies, at first glance, fully justified their existence and confirmed their high efficiency, but the question remains of stopping acute conditions in outpatient conditions when performing invasive procedures and complications that develop after their implementation. It is fair to say that hospitals in this situation have more opportunities to manage patients with urgent conditions. Considering an example of a prostate biopsy, the three most common complications should be highlighted: acute urinary retention, rectal bleeding, and acute inflammatory diseases of the genitourinary system. Several factors were called upon to neutralize these conditions: firstly, the specific prevention of these complications is carried out; secondly, the postoperative management of patients according to generally accepted algorithms that allow clinically insignificant rectal bleeding to stop in a short time. Separately, it should be noted that there is continuity between the outpatient unit and the stations in Moscow. This connection is regulated and supported by the main specialists of the city. Given the presence of one of the fundamental factors, the outpatient city center has the ability to urgently refer the patient to the hospital in case of an emergency.

In the urology department of the branch number 2 GP number 195 for the period 20102017 prostate biopsy in $20(1 \%)$ patients was complicated by rectal hemorrhage, in $17(0.8 \%)$ patients in the immediate postoperative period developed acute orchiepididymitis, in one patient $(0.04 \%)$ - acute urinary retention, in three patients $(0.14 \%)$ there was a brief loss of consciousness during the manipulation. Some patients with non-invasion of an acute condition were urgently hospitalized in hospitals of the Western Administrative District of Moscow.

\section{Discussion}

In summary, it should be noted that the results of a number of studies, as well as our study, stationary technology in the short years of its existence and deservedly included in the practice of the routine of the centers $[19,20]$. Work in this direction is going on, maybe not as quickly as we would like, but it is already bearing fruit in the form of saving financial resources of domestic health care by redirecting the flow of certain invasive procedures and small surgical interventions to the outpatient unit, thereby allowing hospital beds to be relieved, for carrying out volume, costly surgical interventions that require a long stay of the patient under the round-the-clock supervision of the hospital physician. 


\section{Conclusion}

1. Inpatient technologies and techniques can reduce the burden on hospitals.

2. The development of hospital-replacing forms of medical care is determined, on the one hand, by the need of the population for this type of medical services, on the other, by the need for rational and efficient use of financial resources and material and technical resources of health care, that is, the objective need of the health care system itself acting in real social economic environment.

\section{References}

[1] The health care development strategy of the Russian Federation for the long-term period 20152030 (2014). Federal Law 28.06.2014 No. 172-FZ. On Strategic Planning in the Russian Federation.

[2] Safonicheva, O. G., Martynchik, S. A. (2015). The objectives of the development of the scientific platform of medical science "preventive environment": technological solutions. Successes of modern science, 3, 102-106.

[3] Seisen, T., Rouprêt, M., Faix, A. (2012). The prostate gland: a crossroad between the urinary and the seminal tracts. Prog Urol, 22, 2-6. doi: http://doi.org/10.1016/s1166-7087(12)70028-3

[4] Vinjamoori, A. H., Jagannathan, J. P., Shinagare, A. B., Taplin, M.-E., Oh, W. K., Van den Abbeele, A. D., Ramaiya, N. H. (2012). Atypical Metastases From Prostate Cancer: 10-Year Experience at a Single Institution. American Journal of Roentgenology, 199 (2), 367-372. doi: http://doi.org/10.2214/ajr.11.7533

[5] Talaiezadeh, A., Tabesh, H., Sattari, A., Ebrahimi, S. (2013). Cancer Incidence in Southwest of Iran: First Report from Khuzestan Population-Based Cancer Registry, 2002-2009. Asian Pacific Journal of Cancer Prevention, 14 (12), 7517-7522. doi: http://doi.org/10.7314/apjcp.2013.14.12.7517

[6] Freedman, M. L., Haiman, C. A., Patterson, N., McDonald, G. J., Tandon, A., Waliszewska, A. et. al. (2006). Admixture mapping identifies 8q24 as a prostate cancer risk locus in African-American men. Proceedings of the National Academy of Sciences, 103 (38), 14068-14073. doi: http://doi.org/10.1073/pnas.0605832103

[7] Jemal, A., Siegel, R., Ward, E., Hao, Y., Xu, J., Murray, T., Thun, M. J. (2008). Cancer Statistics, 2008. CA: A Cancer Journal for Clinicians, 58 (2), 71-96. doi: http://doi.org/10.3322/ca.2007.0010

[8] Arnold, M., Karim-Kos, H. E., Coebergh, J. W., Byrnes, G., Antilla, A., Ferlay, J. et. al. (2015). Recent trends in incidence of five common cancers in 26 European countries since 1988: Analysis of the European Cancer Observatory. European Journal of Cancer, 51 (9), 1164-1187. doi: http://doi.org/10.1016/ j.ejca.2013.09.002

[9] Nosov, D. A., Vorobyev, N. A., Gladkov, O. A., Koroleva, I. A., Matveev, V. B., Rusakov, I. G. (2016). Practical recommendations for the medicinal treatment of prostate cancer. Malignant tumors, 4 (2), 343-352.

[10] Chissov, V. I., Rusakov, I. G. (2011). The incidence of prostate cancer in the Russian Federation. Experimental and clinical urology, 2-3, 6-7.

[11] Kaprin, A. D., Starinskij, V. V., Petrova, G. V. (2013). The state of cancer care in Russia in 2012. Moscow, 231.

[12] Daniyal, M., Siddiqui, Z. A., Akram, M., Asif, H. M., Sultana, S., Khan, A. (2014). Epidemiology, Etiology, Diagnosis and Treatment of Prostate Cancer. Asian Pacific Journal of Cancer Prevention, 15 (22), 9575-9578. doi: http://doi.org/10.7314/apjcp.2014.15.22.9575

[13] Pushkar, D. Yu., Rasner, P. I., Kupriyanov, Yu. A., Malcev, E. G., Gurov, E. Yu., Umyarov, M. S., Sidorenkov, A. V. (2014). Prostate cancer. Russian medical journal, 17, 5.

[14] Zheng, X.-Y., Zhang, P., Xie, L.-P., You, Q.-H., Cai, B.-S., Qin, J. (2012). Prostate-specific Antigen Velocity (PSAV) and PSAV per Initial Volume (PSAVD) for Early Detection of Prostate Cancer in Chinese Men. Asian Pacific Journal of Cancer Prevention, 13 (11), 5529-5533. doi: http://doi.org/10.7314/ apjcp.2012.13.11.5529

[15] Rogatsch, H., Moser, P., Volgger, H., Horninger, W., Bartsch, G., Mikuz, G., Mairinger, T. (2000). Diagnostic effect of an improved preembedding method of prostate needle biopsy specimens. Human Pathology, 31 (9), 1102-1107. doi: http://doi.org/10.1053/hupa.2000.9837

[16] Prilepskaya, E. A., Kovylina, M. V., Govorov, A. V., Vasilyev, A. O., Sadchenko, A. V., Pushkar, D. Yu. (2016). Histological features of prostate cancer. Experimental and clinical urology, 4, 56-58. 
[17] Schröder, F. H., Hugosson, J., Roobol, M. J., Tammela, T. L. J., Ciatto, S., Nelen, V. et. al. (2009). Screening and Prostate-Cancer Mortality in a Randomized European Study. New England Journal of Medicine, 360 (13), 1320-1328. doi: http://doi.org/10.1056/nejmoa0810084

[18] Zhane, A. K. (2000). Ways to improve inpatient care during the period of health care reform. Saint Petersburg, 23.

[19] Pavlov, Yu. V. (2002). Medical and organizational bases of improvement of work of hospitals of intensive treatment in the conditions of reforming of inpatient care. Saint Petersburg, 40.

\title{
DIAGNOSTIC VALUE OF MORPHOLOGICAL CHANGES IN GASTROESOPHAGEAL REFLUX DISEASE IN BIOPSY MATERIAL OF THE DISTAL ESOPHAGUS IN ADOLESCENTS SICKLY WITH ACUTE RESPIRATORY DISEASES
}

\author{
Olena Zhuravel \\ Department of Pediatrics No. 1 \\ A. A. Bogomolets National Medical University \\ T. Shevchenko blvd., 13, Kyiv, Ukraine, 01601 \\ Tetyana Pochinok \\ Department of Pediatrics No. 1 \\ A. A. Bogomolets National Medical University \\ T. Shevchenko blvd., 13, Kyiv, Ukraine, 01601 \\ Tamara Zadorozhna \\ Department of Pathological \\ Institute of Pediatrics, Obstetrics and Gynecology of NAMS of Ukraine \\ 8 Platona Mayborody str., Kyiv, Ukraine, 04050 \\ Tetyana Archakova \\ Department of Pathological \\ Institute of Pediatrics, Obstetrics and Gynecology of NAMS of Ukraine \\ 8 Platona Mayborody str., Kyiv, Ukraine, 04050 \\ Valentyna Zamula \\ Children's Clinical Hospital No. 9 Podolsk district \\ 1/7 Kopilivska str., Kyiv, Ukraine, 04073
}

\footnotetext{
Abstract

The article dedicated to the problem of the diagnostic value of morphological changes in gastroesophageal reflux disease in the biopsy of the distal esophagus in pubertal children of childbearing age.

Aim of the research is to investigate the diagnostic value of morphological changes in gastroesophageal reflux disease in esophageal biopsy material in adolescents sickly with acute respiratory diseases.

Methodology. The objective of the study was achieved through examination of 90 adolescents (10 to 16 years old, average age 13.1 \pm 3.54 years) kept under observation at the Children's Clinical Hospital No. 9 of Kyiv and on the basis of the Department of Pediatrics No. 1 Center of Primary Health Care No. 4 of the Desnianskyi district of Kyiv. All adolescents belonged to the group of sickly with a number of respiratory diseases averaging 6-8 times a year, lasting from 8 to 18 days (on average 12.8 \pm 5.41 days). All children have undergone endoscopic examination of the esophagus, stomach and duodenum with the esophagus mucosa biopsy using the OLYMPUS GIF-P3 flexible fiberscope.
} 